\title{
Reform of the classification and evaluation system for scientific and technological innovation talents in the intelligent age
}

\author{
Xiaoqing Wang*,Chunxiao Mu \\ Xi’an Jiaotong University City College, Xi'an city, Shaanxi Prov. P.R.China
}

\begin{abstract}
The existing evaluation system of scientific and technological talents is insufficient in classification and evaluation, lacks clear evaluation objectives and evaluation standards, and attaches too much importance to the achievements of scientific and technological talents and lacks the development potential of scientific and technological talents. In this paper, using intelligent era information technology reform of science and technology talent assessment system, to advocate and innovation for the purpose, classification of evaluation objects, evaluation criterion of explicit, the diversification of evaluation subject, evaluation method is scientific, the diversification of evaluation methods, to effectively identify innovative science and technology talents, motivating talents of science and technology innovation power and guide the scientific and technological personnel work to lay the foundation.
\end{abstract}

\section{Introduction}

Talent is the key to China's efforts to promote comprehensive innovation with scientific and technological innovation as the core. Exploring to establish a scientific classification of qualified personnel in science and technology evaluation index system and method, can give full play to the talent evaluation guidance and incentive, guide the scientific and technological personnel with great concentration in research and innovation, help management department to identify as early as possible and find creative potential youth science and technology talents, science and technology leader, have made outstanding contributions to the distribution of the elements of science and technology resources to the innovative science and technology talents converging, improve the efficiency of resource utilization of science and technology, to be better faster development lays the foundation for scientific and technological innovation.

\section{Literature review}

The existing literature and practice have defined the concept, classification and characteristics of scientific and technological talents. The research on the evaluation of scientific and technological talents focuses on the evaluation methods and indexes. The theoretical research and management practice have made a lot of achievements in the evaluation of scientific and technological talents, but the effect and quality of the evaluation of scientific and technological talents are difficult to obtain the satisfaction of the government and the public, resulting in the failure to effectively mobilize the enthusiasm of scientific and technological talents, the lack of scientific and technological innovation, the utilitarian and short-sightedness of the work of talents.

\subsection{The phenomenon of insufficient classification and evaluation of scientific and technological talents is obvious}

First, most scholars did not classify scientific and technological talents, but only constructed a general evaluation index system. Second, some scholars have classified the scientific and technological talents, but have not constructed the evaluation index system for each type of scientific and technological talents. Third, although some scholars have classified scientific and technological talents and indeed tried to build a classification evaluation index system, they have not given different evaluation systems for further classifying talents.

\subsection{Lack of clear evaluation objectives and evaluation criteria}

Although there have been a lot of research literature on the evaluation of innovative scientific and technological talents, the problem of how to identify innovative scientific and technological talents and how to motivate and stimulate their innovation motivation has not been solved because the above evaluation purpose itself is not clear[1]. The purpose of the existing evaluation index system for scientific and technological talents is not clear whether it is used for performance assessment, talent identification, or professional title assessment. As a result, the designed evaluation indexes are not targeted, which seem to cover all aspects but are not practical and have poor application effect. According to performance

\footnotetext{
* Corresponding author: wang.xq@163.com
} 
management theory, evaluation indicators, evaluation methods and evaluation criteria all depend on the purpose of evaluation. Different evaluation purposes, the evaluation indicators, evaluation criteria and evaluation subjects are bound to have differences and focuses.

\subsection{Over-emphasis has been placed on the achievements of scientific and technological talents, and the development potential of scientific and technological talents has been lacking}

Although the discussion about individual potential is often found in the literature, there is a lack of specific design and application of such evaluation indicators[2]. In the selection of evaluation indexes, they generally focus on moral character, ability and performance, many of which are difficult to verify, and the weight of evaluation indexes is not clear. In building a talent evaluation system, often failed to revolve around the starting point of innovation, meet the requirement of the nature of innovation in each evaluation dimensions, performance, the final result, which is not conducive to identify innovative talents, guide and encourage scientific and technological personnel engaged in innovation, weakened the effect on evaluation system for the promotion of scientific and technological innovation.

\section{Overall design of evaluation system}

Different types of scientific and technological talents have their own characteristics, and there is no universally applicable evaluation system that can scientifically evaluate all types of scientific and technological talents. Therefore, the evaluation of scientific and technological talents should be based on the scientific classification of talents, and different evaluation indexes and standards should be adopted for different types of scientific and technological talents. Emerging technologies represented by big data and artificial intelligence provide convenience for the diversification of talent evaluation methods[3]. For example, the evaluation based on big data analysis technology can not only collect data from the R\&D process of scientific and technological talents in all directions and the whole process, but also obtain unstructured data such as emotional factors, psychological tendency and practical ability. To reconstruct the evaluation system of scientific and technological talents and to deepen the reform of talent evaluation by using the information technology in the intelligent age, we must provide targeted solutions in the aspects of evaluation contents, evaluation subjects, evaluation methods and evaluation tools.

\subsection{Talent classification}

According to the horizontal innovation chain of work nature and functional field, scientific and technological talents can be divided into basic research talents, application and research talents, and scientific and technological service management talents. At the same time, from the vertical dimension of career growth, talents can be divided into rising talents (primary), soaring talents (intermediate) and top talents (senior).

\subsection{Talent characteristics and evaluation indicators}

Through the analysis of the characteristics of innovative scientific and technological talents, it is concluded that the scientific and technological talents should have the characteristics of common and individual, including the characteristics of psychological behavior, knowledge and skills, scientific research achievements and scientific research contributions, in order to engage in innovative scientific and technological work[4]. In the design of evaluation system, outstanding innovation, through literature study, expert investigation method, word frequency analysis method, finally establish contains innovation quality, innovation ability, innovation performance and contribution to the four dimensions of evaluation indexes, the innovation quality, performance and contribution are included in the evaluation system, consists of the secondary and tertiary indicators.

\subsection{Evaluation subject}

This paper selects evaluation subjects according to the spirit of Guiding Opinions on Promoting the Reform of Talent Evaluation Mechanism by Classification[5], and uses expert interview method and Delphi method to determine the multi-dimensional and multi-level evaluation subjects. Specifically, it includes government departments, employers, peers, intermediaries, and the public, etc. Finally, a 360-degree comprehensive evaluation method is adopted to improve the professionalism and fairness of the evaluation of innovative scientific and technological talents.

\subsection{Evaluation criteria}

Scientific and technological talents should aim at creating new theories, overturning new technologies and filling new gaps, carry out the basic ideas and principles of classified evaluation, and get rid of the undesirable tendency of only focusing on papers and achievements. For different types and levels of scientific and technological talents, different evaluation indexes and standards should be applied respectively. In general, the evaluation of talents in basic research focuses on their innovation ability and innovation contribution, emphasizes the evaluation of academic and technical level, and pays attention to the quality of research results and their influence on the country and society. To the application and technology research and development personnel, focus on the evaluation of innovation achievements, technological achievements transfer and transformation; In terms of scientific and technological service and management talents, emphasis is placed on the evaluation of social and economic benefits, with emphasis on the evaluation of the benefits of transformation of scientific and technological 
achievements, and on the economic benefits such as output value and profit, as well as the social benefits such as employment absorption and resource and environmental protection[6].

Growth is dynamic, development of science and technology talents, talents of science and technology innovation characteristics of different stages have different career cycle, therefore, in the evaluation of scientific and technological personnel, should also consider the characteristics of scientific and technological personnel in different career stage, in the design of evaluation index weight, in order to reflect the phase talents' qualities, which will help to find creative potential talent. Gold period of science and technology talent is the youth, in order to better promote the youth science and technology talents growth, better find star science and technology, especially need to consider the time dimension on the evaluation index system design, will not show the scientific and technological achievements of innovative young scientific and technological personnel to dig out as soon as possible, give them matching research condition and the hardware and software support, help them better growth. To be specific, we emphasize on the evaluation of junior talents' innovation potential, innovation knowledge and innovation spirit. For intermediate talents, emphasis is placed on evaluating their innovation potential, innovation performance and contribution. For senior talents, emphasis is placed on the evaluation of their innovative achievements and contributions, as well as the training of innovative talents and the effectiveness of innovative team management.

\section{Evaluation index system design}

\subsection{Evaluation principle}

The innovation-oriented classification and evaluation of scientific and technological talents follows the following principles:

First, according to different careers, different positions, different characteristics of talents, and responsibility, adhere to the commonness and particularity, the level of performance and development potential, and the combination of qualitative and quantitative evaluation, classification of building the innovation consciousness, innovation ability and innovation performance, contribute elements such as innovation, scientific and reasonable, with emphasis on talent evaluation standard.

Second, we should insist on evaluating talents by their ability (potential), actual performance and contribution. We should overcome the tendency to only rely on academic qualifications, qualifications and papers, and pay attention to examining the professional, innovative and responsibility performance, innovative achievements and actual contributions of all kinds of talents.

Thirdly, it follows the law of talent growth, reflects the differences in performance, ability (potential) and contribution of different types of talents at different stages of their career, and establishes differentiated evaluation criteria in the time dimension.

\subsection{Evaluation index}

Based on the literature research results, through the analysis of the connotation of innovative scientific and technological talents, combined with the competency model theory, this paper preliminarily designs the innovation-oriented evaluation index of scientific and technological talents. Further decomposition of refining, classification, filtering, merging, and through expert interview, this paper uses the fuzzy analytic hierarchy process (AHP), frequency analysis and experience judgment method, finally established the evaluation index system of innovation of science and technology talents classification, which contains 4 first-level indicators (innovation quality, innovation ability, innovation performance, innovation contribution) and 12 secondary indicators and 29 tertiary index (be omitted), such as table 1.

Table1. Evaluation indexes of innovation-oriented scientific and technological talents

\begin{tabular}{|c|c|c|}
\hline Level 1 & Level 2 & $\begin{array}{r}\text { Level } 3 \\
\text { (Index } \\
\text { amount) }\end{array}$ \\
\hline \multirow{2}{*}{$\begin{array}{l}\text { 1Innovation } \\
\text { quality }\end{array}$} & 1.1Moral of Innovation & 2 \\
\hline & 1.2Innovation consciousness & 3 \\
\hline \multirow{4}{*}{$\begin{array}{l}\text { 2Innovation } \\
\text { ability }\end{array}$} & 2.1knowledge structure & 3 \\
\hline & 2.2learning ability & 3 \\
\hline & 2.3R\&D ability & 4 \\
\hline & 2.4 management ability & 2 \\
\hline \multirow{2}{*}{$\begin{array}{l}\text { 3Innovation } \\
\text { performance }\end{array}$} & 3.1innovative product & 3 \\
\hline & 3.2research subject & 2 \\
\hline \multirow{4}{*}{$\begin{array}{l}\text { 4Innovation } \\
\text { contribution }\end{array}$} & $\begin{array}{l}\text { 4.1Science and technology } \\
\text { breakthrough }\end{array}$ & 3 \\
\hline & 4.2Science and technology awards & 1 \\
\hline & 4.3achievement transformation & 2 \\
\hline & 4.4talent cultivation & 1 \\
\hline
\end{tabular}

\subsection{Index weight}

Talent based on the basic research of primary (new talent), intermediate (intermediate talent), advanced stage (advanced talent) as an example, the design level of the weight of indicators and secondary indicators (table 2), applied research and technology development and experiment technology talents, social commonweal research and science and technology management and service personnel of junior high school senior design method of evaluation index is similar. 
Table2. The weight design of talent evaluation index in basic research

\begin{tabular}{|c|c|c|c|}
\hline Level 2 index & New talent & $\begin{array}{c}\text { Intermediate } \\
\text { talent }\end{array}$ & $\begin{array}{c}\text { Advanced } \\
\text { talent }\end{array}$ \\
\hline 1.1 & 5 & 5 & 3 \\
\hline 1.2 & 15 & 10 & 5 \\
\hline 2.1 & 15 & 10 & 5 \\
\hline 2.2 & 15 & 10 & 5 \\
\hline 2.3 & 10 & 10 & 5 \\
\hline 2.4 & 5 & 5 & 10 \\
\hline 3.1 & 10 & 15 & 18 \\
\hline 3.2 & 10 & 10 & 12 \\
\hline 4.1 & 3 & 5 & 10 \\
\hline 4.2 & 2 & 4 & 7 \\
\hline 4.3 & 6 & 8 & 10 \\
\hline 4.4 & 4 & 8 & 10 \\
\hline Total & 100 & 100 & 100 \\
\hline
\end{tabular}

\section{Conclusion and Prospect}

This paper takes innovation as the fundamental requirement, evaluation standard and incentive goal of talent evaluation, and takes innovation accomplishment, innovation ability, innovation performance and innovation contribution as the important dimensions of science and technology talent evaluation, and constructs the framework and index system of innovation-oriented science and technology talent classification evaluation system. The system is based on the nature of innovation design innovative talents evaluation index system, combining the scientific and technological personnel transverse professional characteristics and characteristics of longitudinal career stage two dimensions, in the main choice for the government, enterprises and peer related subject, intermediary and social interests, between these two factors, under the constraint of differentiation of evaluation index weight is designed. The application of this system has practical application value for effectively identifying and discovering innovative scientific and technological talents and stimulating their innovation motivation.

For horizontal talents of various types and vertical talents of various levels, the connotation and evaluation criteria of the evaluation indicators are different, which need to be scientifically designed according to the actual situation. Before applying the evaluation system, the evaluation criteria of each indicator should be further clarified. Evaluation is not the goal, and any evaluation system has certain limitations. The most fundamental purpose of the innovation-oriented talent classification evaluation system constructed in this paper is to find and identify innovative scientific and technological talents, and to lay a foundation for the use, performance allocation and resource allocation of innovative scientific and technological talents. The evaluation system may not be applicable to the annual performance evaluation of talent management, job promotion, staff training and other purposes.

\section{Foundation item:}

Innovation Capability Support Program of Shaanxi (Program No. 2020KRM207)

\section{References}

1. Silzer R., Church A. The Potential for Potential. Industrial and Organizational Psychology. 4(2009).

2. SHENG Nan, MENG Fanxiang, JIANG Bin, et al. Research on the construction of scientific and technological talent evaluation system under innovation-driven strategy. Science Research Management, 37, S1 (2016).

3. Zhang Wei, Wang Liang, Qian Heyi. Core Literacy of Scientific and Technological Talents in Intelligent Social Engineering: Element Identification and Cultivation Strategy.Research in Higher Engineering Education, 4(2020).

4. Zhao Wei, Bao Xianhua, Qu Baoqiang, Lin Fenfen. Science and Technology Progress and Countermeasures, 30, 16 (2013) .

5. Department of Science and Technology, National Medium - and Long-Term Program for Scientific and Technological Talents Development (2010-2020) . ( Science and Technology Literature Press,2011).

6. Yang Yuekun, Lu Nan. Construction of evaluation model of innovative talents of science and technology based on knowledge value.Leadership Science, 2(2019) 